\title{
Convergence theorems for generalized nonexpansive mappings in uniformly convex Banach spaces
}

\author{
Dipti Thakur ${ }^{1}$, Balwant Singh Thakur ${ }^{1}$ and Mihai Postolache $2^{2 *}$
}

\section{"Correspondence:}

emscolar@yahoo.com

${ }^{2}$ Department of Mathematics \& Informatics, University Politehnica of Bucharest, Bucharest, 060042, Romania

Full list of author information is available at the end of the article

\begin{abstract}
In this paper, we prove strong and weak convergence theorems for a mapping defined on a bounded, closed and convex subset of a uniformly convex Banach space, satisfying the RCSC condition. This condition was introduced by Karapınar (Dynamical Systems and Methods, 2012). We first establish the demiclosed principle for the mapping satisfying the RCSC condition. Then, using this principle, we establish the weak and strong convergence theorems. Results in the paper extend and improve a number of important results in this literature such as Khan and Suzuki (Nonlinear Anal. 80:211-215, 2013) and Reich (J. Math. Anal. Appl. 67:274-276, 1979).
\end{abstract}

MSC: $47 \mathrm{H} 09 ; 47 \mathrm{H} 10$

Keywords: generalized nonexpansive mappings; fixed points; convergence theorem; uniformly convex Banach space

\section{Introduction}

Let $C$ be a nonempty closed convex subset of a Banach space $X$. A mapping $T: C \rightarrow C$ is said to be nonexpansive if $\|T x-T y\| \leq\|x-y\|$ for all $x, y \in C$. It is called quasinonexpansive [1] if $F(T) \neq \emptyset$ and $\|T x-p\| \leq\|x-p\|$ for all $x \in C$ and for all $p \in F(T)$, where $F(T)$ is the set of fixed points of $T$, i.e., $F(T)=\{x \in C: T x=x\}$. Every nonexpansive mapping with $F(T) \neq \emptyset$ is a quasi-nonexpansive mapping.

In 2008, Suzuki [2] introduced a mapping satisfying condition (C). More accurately, a mapping $T: C \rightarrow C$ is said to satisfy condition (C) if

$$
\frac{1}{2}\|x-T x\| \leq\|x-y\| \quad \Longrightarrow \quad\|T x-T y\| \leq\|x-y\|
$$

for all $x, y \in C$. Every nonexpansive mapping satisfies condition (C); also if a mapping satisfies condition $(C)$ and has a fixed point, then it is a quasi-nonexpansive mapping [2].

Fixed point theorems for a mapping satisfying condition $(C)$ were studied by Dhompongsa et al. [3] and Phuengrattana [4]. Khan and Suzuki [5] proved a weak convergence theorem for a mapping satisfying condition $(C)$ in uniformly convex Banach spaces whose dual has the Kadec-Klee property.

In 2013, Karapinar [6] suggested a new modification of mappings satisfying condition (C) to a mapping satisfying (RCSC)-condition.

\section{照 Springer}


Definition 1.1 Let $T$ be a mapping on a subset $C$ of a Banach space $X$. Then $T$ is said to satisfy Reich-Chatterjea-Suzuki-(C) condition ((RCSC)-condition) if

$$
\frac{1}{2}\|x-T x\| \leq\|x-y\| \quad \Longrightarrow \quad\|T x-T y\| \leq \frac{1}{3}(\|x-y\|+\|T x-y\|+\|x-T y\|)
$$

for all $x, y \in C$.

Motivated by the above mentioned works, in this paper, we prove some weak and strong convergence theorems for generalized nonexpansive ((RCSC)-condition) mappings in a uniformly convex Banach space, which has the Kadec-Klee property. Our results generalize the results of Khan and Suzuki [5], Reich [7] to the case of a mapping satisfying (RCSC)condition. For other works in this direction, please see Mogbademu [8], Saluja [9], Thakur [10] and Zheng [11].

\section{Preliminaries}

Throughout this paper, we denote by $\mathbb{N}$ the set of positive integers and by $\mathbb{R}$ the set of real numbers.

We now recall some definitions and results useful for our main results.

A Banach space $X$ is called uniformly convex [12] if for each $\varepsilon \in(0,2]$ there is $\delta>0$ such that for $x, y \in X$,

$$
\left.\begin{array}{r}
\|x\| \leq 1 \\
\|y\| \\
\|x-y\| \\
\| \varepsilon
\end{array}\right\} \Rightarrow\left\|\frac{x+y}{2}\right\| \leq \delta .
$$

Lemma 2.1 ([12]) Let $X$ be a uniformly convex Banach space. Let $\left\{x_{n}\right\}$ and $\left\{y_{n}\right\}$ be sequences in $X$ satisfying $\lim _{n \rightarrow \infty}\left\|x_{n}\right\|=1, \lim _{n \rightarrow \infty}\left\|y_{n}\right\|=1$ and $\lim _{n \rightarrow \infty}\left\|x_{n}+y_{n}\right\|=2$. Then $\lim _{n \rightarrow \infty}\left\|x_{n}-y_{n}\right\|=0$.

Lemma $2.2([5])$ Let $X$ be a uniformly convex Banach space and let $\left\{u_{n}\right\},\left\{v_{n}\right\}$ and $\left\{w_{n}\right\}$ be sequences in $X$. Let $d$ and $t$ be real numbers with $d \in(0, \infty)$ and $t \in(0,1)$. Assume that $\lim _{n \rightarrow \infty}\left\|u_{n}-v_{n}\right\|=d, \limsup _{n \rightarrow \infty}\left\|u_{n}-w_{n}\right\| \leq(1-t) d$ and $\limsup _{n \rightarrow \infty}\left\|v_{n}-w_{n}\right\| \leq t d$. Then $\lim _{n \rightarrow \infty}\left\|t u_{n}+(1-t) v_{n}-w_{n}\right\|=0$.

Proposition 2.1 Let $C$ be a nonempty subset of a Banach space $X$ and $T: C \rightarrow C$ be a mapping satisfying (RCSC)-condition. Then $T$ has the following properties:

(i) If $T$ has a fixed point, then it is a quasi-nonexpansive mapping [6], Proposition 6.

(ii) If $C$ is closed, then $F(T)$ is closed; further if $X$ is strictly convex and $C$ is convex, then $F(T)$ is also convex [6], Proposition 10.

A Banach space $X$ is said to have the Kadec-Klee property if, for every sequence $\left\{x_{n}\right\}$ in $X$ which converges weakly to a point $x \in X$ with $\left\|x_{n}\right\|$ converging to $\|x\|,\left\{x_{n}\right\}$ converges strongly to $x$. Every uniformly convex Banach space has the Kadec-Klee property [13].

Lemma $2.3([14,15])$ Let $X$ be a reflexive Banach space whose dual has the Kadec-Klee property. Let $\left\{x_{n}\right\}$ be a bounded sequence in $X$ and let $y, z \in X$ be weak subsequential limits of $\left\{x_{n}\right\}$. Assume that for every $t \in[0,1], \lim _{n \rightarrow \infty}\left\|t x_{n}+(1-t) y-z\right\|$ exists. Then $y=z$. 
Proposition 2.2 Let $C$ be a nonempty subset of a Banach space $X$ and $T: C \rightarrow C$ be a mapping satisfying (RCSC)-condition. Then

(1) $\|x-T y\| \leq 9\|T x-x\|+\|x-y\|$,

(2) $\|y-T y\| \leq 9\|T x-x\|+2\|x-y\|$

hold for all $x, y \in C$.

Proof (1) follows from [6], Corollary 16.

For (2), it follows from (1) that

$$
\begin{aligned}
\|y-T y\| & \leq\|y-x\|+\|x-T y\| \\
& \leq 9\|x-T x\|+2\|x-y\| .
\end{aligned}
$$

Thus we have (2).

\section{Main results}

In this section, we prove weak and strong convergence theorems. First, we establish some auxiliary results.

The following lemma is an extension of Lemma 8 of [5] to the case of mappings satisfying (RCSC)-condition.

Lemma 3.1 Let $C$ be a nonempty bounded convex subset of a uniformly convex Banach space $X$, and let $T: C \rightarrow C$ be a mapping satisfying (RCSC)-condition. Suppose that for any $\varepsilon>0$, there exists $\xi(\varepsilon)>0$ such that $\|T u-u\|<\xi(\varepsilon),\|T v-v\|<\xi(\varepsilon)$ for some $u, v \in C$. Then, for any $t \in[0,1]$,

$$
\|T(t u+(1-t) v)-(t u+(1-t) v)\|<\varepsilon .
$$

Proof Assume to the contrary that there exist sequences $\left\{u_{n}\right\},\left\{v_{n}\right\} \in C,\left\{t_{n}\right\} \in[0,1]$ and $\varepsilon>0$ such that

$$
\left\|T u_{n}-u_{n}\right\|<\frac{1}{n}, \quad\left\|T v_{n}-v_{n}\right\|<\frac{1}{n}
$$

and

$$
\left\|T\left(t_{n} u_{n}+\left(1-t_{n}\right) v_{n}\right)-\left(t_{n} u_{n}+\left(1-t_{n}\right) v_{n}\right)\right\| \geq \varepsilon
$$

Setting $x_{n}=t_{n} u_{n}+\left(1-t_{n}\right) v_{n}$ and $w_{n}=T x_{n}$, from Proposition 2.2(ii), we get

$$
\begin{aligned}
0 & <\varepsilon \leq \liminf _{n \rightarrow \infty}\left\|T x_{n}-x_{n}\right\| \\
& \leq \liminf _{n \rightarrow \infty}\left(9\left\|T u_{n}-u_{n}\right\|+2\left\|u_{n}-x_{n}\right\|\right) \\
& =2 \liminf _{n \rightarrow \infty}\left\|u_{n}-x_{n}\right\| .
\end{aligned}
$$

Similarly, we can show that

$$
0<\liminf _{n \rightarrow \infty}\left\|v_{n}-x_{n}\right\|
$$


and hence

$$
0<\liminf _{n \rightarrow \infty}\left\|u_{n}-v_{n}\right\|
$$

Since $C$ is bounded and

$$
0<\liminf _{n \rightarrow \infty}\left\|v_{n}-x_{n}\right\|=\liminf _{n \rightarrow \infty} t_{n}\left\|u_{n}-v_{n}\right\| \leq \liminf _{n \rightarrow \infty} t_{n} \times \sup _{n \in \mathbb{N}}\left\|u_{n}-v_{n}\right\|,
$$

we get $0<\liminf _{n \rightarrow \infty} t_{n}$.

Similarly, we can show that $\limsup _{n \rightarrow \infty} t_{n}<1$.

So, without loss of generality, we may assume that $\left\|u_{n}-v_{n}\right\|$ converges to $d \in(0, \infty)$ and $t_{n}$ converges to $t \in(0,1)$ as $n \rightarrow \infty$.

Since $\lim _{n \rightarrow \infty}\left\|T u_{n}-u_{n}\right\|=0$ and $0<\liminf _{n \rightarrow \infty}\left\|u_{n}-x_{n}\right\|$, we obtain

$$
\frac{1}{2}\left\|T u_{n}-u_{n}\right\| \leq\left\|u_{n}-x_{n}\right\|
$$

for sufficiently large $n \in \mathbb{N}$.

Since $T$ satisfies (RCSC)-condition, for sufficiently large $n \in \mathbb{N}$, we have

$$
\left\|T u_{n}-T x_{n}\right\| \leq \frac{1}{3}\left(\left\|u_{n}-x_{n}\right\|+\left\|T u_{n}-x_{n}\right\|+\left\|u_{n}-T x_{n}\right\|\right) .
$$

By similar arguments, we have

$$
\left\|T v_{n}-T x_{n}\right\| \leq \frac{1}{3}\left(\left\|v_{n}-x_{n}\right\|+\left\|T v_{n}-x_{n}\right\|+\left\|v_{n}-T x_{n}\right\|\right)
$$

for sufficiently large $n \in \mathbb{N}$.

Now, using the triangular inequality and Proposition 2.2(i), we have

$$
\begin{aligned}
& \limsup _{n \rightarrow \infty}\left\|u_{n}-w_{n}\right\| \\
& \quad \leq \limsup _{n \rightarrow \infty}\left(\left\|u_{n}-T u_{n}\right\|+\left\|T u_{n}-T x_{n}\right\|\right) \\
& \quad \leq \limsup _{n \rightarrow \infty}\left(\left\|u_{n}-T u_{n}\right\|+\frac{1}{3}\left(\left\|u_{n}-x_{n}\right\|+\left\|T u_{n}-x_{n}\right\|+\left\|u_{n}-T x_{n}\right\|\right)\right) \\
& \quad \leq \limsup _{n \rightarrow \infty}\left(\left\|u_{n}-T u_{n}\right\|+\frac{1}{3}\left(\left\|u_{n}-x_{n}\right\|+10\left\|u_{n}-T u_{n}\right\|+2\left\|u_{n}-x_{n}\right\|\right)\right) \\
& \quad=(1-t) d,
\end{aligned}
$$

and

$$
\begin{aligned}
& \limsup _{n \rightarrow \infty}\left\|v_{n}-w_{n}\right\| \\
& \quad \leq \limsup _{n \rightarrow \infty}\left(\left\|v_{n}-T v_{n}\right\|+\left\|T v_{n}-T x_{n}\right\|\right) \\
& \quad \leq \limsup _{n \rightarrow \infty}\left(\left\|v_{n}-T v_{n}\right\|+\frac{1}{3}\left(\left\|v_{n}-x_{n}\right\|+\left\|T v_{n}-x_{n}\right\|+\left\|v_{n}-T x_{n}\right\|\right)\right)
\end{aligned}
$$




$$
\begin{aligned}
& \leq \limsup _{n \rightarrow \infty}\left(\left\|v_{n}-T v_{n}\right\|+\frac{1}{3}\left(\left\|v_{n}-x_{n}\right\|+10\left\|v_{n}-T v_{n}\right\|+2\left\|v_{n}-x_{n}\right\|\right)\right) \\
& =t d .
\end{aligned}
$$

It then follows from Lemma 2.2 that

$$
0<\varepsilon \leq \lim _{n \rightarrow \infty}\left\|x_{n}-w_{n}\right\|=0
$$

which is a contradiction, and this completes the proof.

We now establish the demiclosed principle for the mapping satisfying (RCSC)-condition.

Proposition 3.1 Let $T$ be a mapping on a bounded and convex subset $C$ of a uniformly convex Banach space X. Assume that T satisfies (RCSC)-condition. Then I-T is demiclosed at zero. That is, if $\left\{x_{n}\right\} \in C$ converges weakly to $x_{0} \in C$ and $\lim _{n \rightarrow \infty}\left\|T x_{n}-x_{n}\right\|=0$, then $T x_{0}=x_{0}$.

Proof Let $\xi:(0, \infty) \rightarrow(0, \infty)$ be a function satisfying the conclusion of Lemma 3.1. Let $\left\{x_{n}\right\}$ be a sequence converging weakly to $x_{0} \in C$ and $\lim _{n \rightarrow \infty}\left\|T x_{n}-x_{n}\right\|=0$. For arbitrarily chosen $\varepsilon>0$, define a strictly decreasing sequence $\left\{\varepsilon_{n}\right\}$ in $(0, \infty)$ by

$$
\varepsilon_{1}=\varepsilon \quad \text { and } \quad \varepsilon_{n+1}=\frac{\min \left\{\varepsilon_{n}, \xi\left(\varepsilon_{n}\right)\right\}}{2} .
$$

It is obvious that $\varepsilon_{n+1}<\xi\left(\varepsilon_{n}\right)$. Choose a subsequence $\left\{x_{f(n)}\right\}$ of $\left\{x_{n}\right\}$ such that $\| x_{f(n)}-$ $T x_{f(n)} \|<\xi\left(\varepsilon_{n}\right)$. Since $x_{0}$ belongs to the closed convex hull of $\left\{x_{f(n)}: n \in \mathbb{N}\right\}$, it is a weak limit of $\left\{x_{f(n)}\right\}$. Hence, there exist $y \in C$ and $v \in \mathbb{N}$ such that $\left\|y-x_{0}\right\|<\varepsilon$ and $y$ belongs to the convex hull of $\left\{x_{f(n)}: n=1,2, \ldots, v\right\}$. Using Lemma 3.1, we have $\|T y-y\|<\varepsilon$. Using Proposition 2.2(ii), we obtain

$$
\left\|T x_{0}-x_{0}\right\| \leq 9\|T y-y\|+2\left\|y-x_{0}\right\|<11 \varepsilon .
$$

Since $\varepsilon>0$ is arbitrary, we obtain $T x_{0}=x_{0}$.

Lemma 3.2 Let $T$ be a mapping on a bounded and convex subset $C$ of a uniformly convex Banach space X. Assume that $T$ satisfies (RCSC)-condition. For arbitrary $x_{1} \in C$ and a real number $\alpha \in[1 / 2,1)$, construct a sequence $\left\{x_{n}\right\}$ in $C$ by

$$
x_{n+1}=\alpha T x_{n}+(1-\alpha) x_{n} .
$$

If $\lim _{n \rightarrow \infty}\left\|T x_{n}-x_{n}\right\|=0$, then $\lim _{n \rightarrow \infty}\left\|t x_{n}+(1-t) p-q\right\|$ exists, where $p, q \in F(T)$ and $t \in[0,1]$.

Proof Since $T$ satisfies (RCSC)-condition, by Proposition 2.1, it is quasi-nonexpansive. Let $S=\alpha T+(1-\alpha) I$, then $S$ is a self-mapping on $C$, and $F(S)=F(T)$ also $S$ is quasinonexpansive, and

$$
x_{n+1}=\alpha T x_{n}+(1-\alpha) x_{n}=S x_{n}=S^{n} x_{1} .
$$


Thus, for any $q \in F(S)$, we have

$$
\begin{aligned}
\left\|x_{n+1}-q\right\| & =\left\|S x_{n}-q\right\| \\
& \leq\left\|x_{n}-q\right\|,
\end{aligned}
$$

hence the sequence $\left\{\left\|x_{n}-q\right\|\right\}$ is nonincreasing and bounded below. Therefore, it converges.

Since the sequence $\{\|p-q\|\}$ obviously converges, we see that $\lim _{n \rightarrow \infty}\left\|t x_{n}+(1-t) p-q\right\|$ exists for $t=1$ and $t=0$. Thus it remains to consider $t \in(0,1)$.

Let $\lim _{n \rightarrow \infty}\left\|x_{n}-p\right\|=d$. If $d=0$, there is nothing to prove. Take $d>0$. We have

$$
\begin{aligned}
\liminf _{m, n \rightarrow \infty}\left\|x_{n}-S^{l}\left(t x_{m}+(1-t) p\right)\right\| & \geq \liminf _{m, n \rightarrow \infty}\left(\left\|x_{n}-p\right\|-\left\|p-S^{l}\left(t x_{m}+(1-t) p\right)\right\|\right) \\
& \geq \liminf _{m, n \rightarrow \infty}\left(\left\|x_{n}-p\right\|-\left\|p-\left(t x_{m}+(1-t) p\right)\right\|\right) \\
& =(1-t) d>0
\end{aligned}
$$

for all $l \in \mathbb{N} \cup\{0\}$, where $S^{0}$ is the identity mapping on $C$. Then there exists $v \in \mathbb{N}$ such that

$$
\frac{1}{2}\left\|x_{n}-T x_{n}\right\| \leq\left\|x_{n}-S^{l}\left(t x_{m}+(1-t) p\right)\right\|
$$

for all $l \geq 0$ and $m, n \geq v$. Since $T$ satisfies (RCSC)-condition and Proposition 2.2(i), we obtain

$$
\begin{aligned}
\left\|T x_{n}-T \circ S^{l}\left(t x_{m}+(1-t) p\right)\right\| & \\
\leq & \frac{1}{3}\left\|x_{n}-S^{l}\left(t x_{m}+(1-t) p\right)\right\|+\frac{1}{3}\left\|T x_{n}-S^{l}\left(t x_{m}+(1-t) p\right)\right\| \\
& +\frac{1}{3}\left\|x_{n}-T \circ S^{l}\left(t x_{m}+(1-t) p\right)\right\|,
\end{aligned}
$$

and hence

$$
\begin{aligned}
&\left\|x_{n+1}-S^{l+1}\left(t x_{m}+(1-t) p\right)\right\| \\
&=\left\|S x_{n}-S \circ S^{l}\left(t x_{m}+(1-t) p\right)\right\| \\
& \leq \| \alpha T x_{n}+(1-\alpha) x_{n}-\alpha T \circ S^{l}\left(t x_{m}+(1-t) p\right) \\
& \quad-(1-\alpha) S^{l}\left(t x_{m}+(1-t) p\right) \| \\
&= \| \alpha\left(T x_{n}-T \circ S^{l}\left(t x_{m}+(1-t) p\right)\right) \\
&+(1-\alpha)\left(x_{n}-S^{l}\left(t x_{m}+(1-t) p\right)\right) \| \\
& \leq \alpha\left\|T x_{n}-T \circ S^{l}\left(t x_{m}+(1-t) p\right)\right\| \\
&+(1-\alpha)\left\|x_{n}-S^{l}\left(t x_{m}+(1-t) p\right)\right\| \\
& \leq \alpha\left\{\frac { 1 } { 3 } \left(\left\|x_{n}-S^{l}\left(t x_{m}+(1-t) p\right)\right\|+\left\|T x_{n}-S^{l}\left(t x_{m}+(1-t) p\right)\right\|\right.\right.
\end{aligned}
$$




$$
\begin{aligned}
& \left.\left.+\left\|x_{n}-T \circ S^{l}\left(t x_{m}+(1-t) p\right)\right\|\right)\right\} \\
& +(1-\alpha)\left\|x_{n}-S^{l}\left(t x_{m}+(1-t) p\right)\right\| \\
\leq & \alpha\left\{\frac { 1 } { 3 } \left(\left\|x_{n}-S^{l}\left(t x_{m}+(1-t) p\right)\right\|+\left\|T x_{n}-S^{l}\left(t x_{m}+(1-t) p\right)\right\|\right.\right. \\
& \left.\left.+9\left\|T x_{n}-x_{n}\right\|+\left\|x_{n}-S^{l}\left(t x_{m}+(1-t) p\right)\right\|\right)\right\} \\
& +(1-\alpha)\left\|x_{n}-S^{l}\left(t x_{m}+(1-t) p\right)\right\| \\
\leq & \alpha\left\{\left\|x_{n}-S^{l}\left(t x_{m}+(1-t) p\right)\right\|+\frac{10}{3}\left\|T x_{n}-x_{n}\right\|\right\} \\
& +(1-\alpha)\left\|x_{n}-S^{l}\left(t x_{m}+(1-t) p\right)\right\| \\
= & \left\|x_{n}-S^{l}\left(t x_{m}+(1-t) p\right)\right\|+\frac{10}{3}\left\|T x_{n}-x_{n}\right\|
\end{aligned}
$$

for all $l \geq 0$ and $m, n \geq v$.

Let $h: \mathbb{N} \rightarrow[0, \infty)$ be a function defined by

$$
h(n)=\left\|t x_{n}+(1-t) p-q\right\| .
$$

Take two subsequences $\{f(n)\}$ and $\{g(n)\}$ of $\{n\}$ such that $v<f(1), f(n)<g(n)$ for each $n \in \mathbb{N}$ and

$$
\lim _{n \rightarrow \infty} h(f(n))=\liminf _{n \rightarrow \infty} h(n), \quad \lim _{n \rightarrow \infty} h(g(n))=\limsup _{n \rightarrow \infty} h(n) .
$$

Set $u_{n}=x_{g(n)}, v_{n}=p$ and $w_{n}=S^{g(n)-f(n)}\left(t x_{f(n)}+(1-t) p\right)$. Then we have

$$
\begin{aligned}
\lim _{n \rightarrow \infty}\left\|u_{n}-v_{n}\right\|=d & \\
\limsup _{n \rightarrow \infty}\left\|u_{n}-w_{n}\right\|= & \limsup _{n \rightarrow \infty}\left\|x_{g(n)}-S^{g(n)-f(n)}\left(t x_{f(n)}+(1-t) p\right)\right\| \\
\leq & \limsup _{n \rightarrow \infty}\left\|x_{f(n)}-\left(t x_{f(n)}+(1-t) p\right)\right\| \\
& +\frac{10}{3} \limsup _{n \rightarrow \infty}\left\|x_{n}-T x_{n}\right\| \\
= & (1-t) \limsup _{n \rightarrow \infty}\left\|x_{f(n)}-p\right\| \\
= & (1-t) d,
\end{aligned}
$$

and

$$
\limsup _{n \rightarrow \infty}\left\|v_{n}-w_{n}\right\| \leq t d .
$$

By (3.2), (3.3), (3.4) and Lemma 2.2, we have

$$
\lim _{n \rightarrow \infty}\left\|t u_{n}+(1-t) v_{n}-w_{n}\right\|=0 .
$$


Substituting the value of $u_{n}, v_{n}$ and $w_{n}$, we have

$$
\lim _{n \rightarrow \infty}\left\|t x_{g(n)}+(1-t) p-S^{g(n)-f(n)}\left(t x_{f(n)}+(1-t) p\right)\right\|=0 .
$$

Using the quasi-nonexpansiveness of $S$, we get

$$
\begin{aligned}
\limsup _{n \rightarrow \infty} h(n)= & \lim _{n \rightarrow \infty} h(g(n)) \\
\leq & \limsup _{n \rightarrow \infty}\left(\left\|t x_{g(n)}+(1-t) p-S^{g(n)-f(n)}\left(t x_{f(n)}+(1-t) p\right)\right\|\right. \\
& \left.+\left\|S^{g(n)-f(n)}\left(t x_{f(n)}+(1-t) p\right)-q\right\|\right) \\
= & \limsup _{n \rightarrow \infty}\left\|S^{g(n)-f(n)}\left(t x_{f(n)}+(1-t) p\right)-q\right\| \\
\leq & \limsup _{n \rightarrow \infty}\left\|\left(t x_{f(n)}+(1-t) p\right)-q\right\| \\
= & \lim _{n \rightarrow \infty} h(f(n)) \\
= & \liminf _{n \rightarrow \infty} h(n) .
\end{aligned}
$$

Thus $\lim _{n \rightarrow \infty} h(n)=\lim _{n \rightarrow \infty}\left\|t x_{n}+(1-t) p-q\right\|$ exists.

Now, we prove a weak convergence theorem.

Theorem 3.1 Let X be a uniformly convex Banach space whose dual has the Kadec-Klee property. Let $T$ be a mapping on a bounded, closed and convex subset $C$ of $X$. Assume that $T$ satisfies (RCSC)-condition and define a sequence $\left\{x_{n}\right\}$ in C by (3.1). If $\lim _{n \rightarrow \infty}\left\|T x_{n}-x_{n}\right\|=$ 0 , then $\left\{x_{n}\right\}$ converges weakly to a fixed point of $T$.

Proof Let $W$ be the set of all weak subsequential limits of $\left\{x_{n}\right\}$. Since $\lim _{n \rightarrow \infty}\left\|T x_{n}-x_{n}\right\|$ is equal to 0 , by Proposition 3.1 we have $W \subset F(T)$. Using Lemma 2.3 and Lemma 3.2, $W$ is singleton. But $X$ is a uniformly convex Banach space, hence reflexive. So every sequence $\left\{x_{n}\right\}$ has a subsequence converging weakly to the unique element of $W$. Since $W$ is singleton, therefore $\left\{x_{n}\right\}$ itself converges weakly to the unique element of $W$.

Remark 1 Theorem 3.1 is a generalization of Theorem 11 of [5].

Since the dual of a reflexive Banach space with Fréchet differentiable norm has the Kadec-Klee property [16], as a direct consequence of Theorem 3.1, we get the following result.

Corollary 3.1 Let $X$ be a uniformly convex Banach space whose norm is Fréchet differentiable. Let $T$ be a mapping on a bounded, closed and convex subset $C$ of $X$. Assume that $T$ satisfies (RCSC)-condition and define a sequence $\left\{x_{n}\right\}$ in C by (3.1). If $\lim _{n \rightarrow \infty}\left\|T x_{n}-x_{n}\right\|=$ 0 , then $\left\{x_{n}\right\}$ converges weakly to a fixed point of $T$.

Recall that a mapping $T: C \rightarrow C$ is said to satisfy condition (I) [17] if there exists a nondecreasing function $f:[0, \infty) \rightarrow[0, \infty)$ with $f(0)=0, f(r)>0$ for all $r \in(0, \infty)$ such that $d(x, T x) \geq f(d(x, F(T)))$ for all $x \in C$, where $d(x, F(T))=\inf _{p \in F(T)} d(x, p)$. 
We now establish a strong convergence theorem.

Theorem 3.2 Let $T$ be a mapping on a bounded, closed and convex subset $C$ of a uniformly convex Banach space X. Assume that T satisfies (RCSC)-condition and define a sequence $\left\{x_{n}\right\}$ in $C$ by (3.1). If $\lim _{n \rightarrow \infty}\left\|T x_{n}-x_{n}\right\|=0$ and $T$ satisfies condition $(I)$, then $\left\{x_{n}\right\}$ converges strongly to a fixed point of $T$.

Proof By Lemma 3.2, we know that $\lim _{n \rightarrow \infty}\left\|x_{n}-p\right\|$ exists for all $p \in F(T)$, and hence $\lim _{n \rightarrow \infty} d\left(x_{n}, F(T)\right)$ exists. Assume that $\lim _{n \rightarrow \infty}\left\|x_{n}-p\right\|=r$ for some $r \geq 0$.

If $r=0$, then $\left\{x_{n}\right\}$ converges strongly to $p$ and the result follows.

Suppose $r>0$. From the hypothesis and condition (I), we have $\lim _{n \rightarrow \infty}\left\|T x_{n}-x_{n}\right\|=0$ and $f\left(d\left(x_{n}, F(T)\right)\right) \leq\left\|T x_{n}-x_{n}\right\|$. This gives $\lim _{n \rightarrow \infty} f\left(d\left(x_{n}, F(T)\right)\right)=0$. Since $f$ is a nondecreasing function, we have $\lim _{n \rightarrow \infty} d\left(x_{n}, F(T)\right)=0$. Thus, there exist a subsequence $\left\{x_{n_{k}}\right\}$ of $\left\{x_{n}\right\}$ and a sequence $\left\{y_{k}\right\} \subset F(T)$ such that

$$
\left\|x_{n_{k}}-y_{k}\right\|<\frac{1}{2^{k}} \quad \text { for all } k \in \mathbb{N} .
$$

Again, we see that

$$
\begin{aligned}
\left\|x_{n+1}-y_{k}\right\| & =\left\|\alpha T x_{n}+(1-\alpha) x_{n}-y_{k}\right\| \\
& \leq \alpha\left\|T x_{n}-y_{k}\right\|+(1-\alpha)\left\|x_{n}-y_{k}\right\| \\
& \leq\left\|x_{n}-y_{k}\right\| \\
& <\frac{1}{2^{k}} .
\end{aligned}
$$

Hence,

$$
\begin{aligned}
\left\|y_{k+1}-y_{k}\right\| & \leq\left\|y_{k+1}-x_{k+1}\right\|+\left\|x_{k+1}-y_{k}\right\| \\
& \leq \frac{1}{2^{k+1}}+\frac{1}{2^{k}} \\
& <\frac{1}{2^{k-1}} \rightarrow 0 \quad \text { as } n \rightarrow \infty .
\end{aligned}
$$

This shows that $\left\{y_{k}\right\}$ is a Cauchy sequence in a complete space, and hence it converges to a point $p \in X$. Since $F(T)$ is closed, therefore $p \in F(T)$ and then $\left\{x_{n_{k}}\right\}$ converges strongly to $p$. Since $\lim _{n \rightarrow \infty}\left\|x_{n}-p\right\|$ exists, $x_{n} \rightarrow p \in F(T)$. This completes the proof.

We now give an example of mapping $T$ which satisfies (RCSC)-condition but fails to satisfy condition $(C)$.

Example 1 Let $X=\mathbb{R}$ with usual metric and $C=[0,1] \subset X$. Define a mapping $T: C \rightarrow C$ by the rule

$$
T x= \begin{cases}0, & x \in\left[0, \frac{4}{5}\right), \\ \frac{x}{2}, & x \in\left[\frac{4}{5}, 1\right] .\end{cases}
$$


Set $x=\frac{9}{10}$ and $y=\frac{3}{5}$, we see that

$$
\frac{1}{2}|x-T x|=\frac{9}{40}<\frac{3}{10}=|x-y|
$$

and

$$
|T x-T y|=\frac{9}{20}>\frac{3}{10}=|x-y|
$$

i.e.,

$$
\frac{1}{2}|x-T x| \leq|x-y| \quad \nRightarrow \quad|T x-T y| \leq|x-y|,
$$

hence, $T$ fails to satisfy condition $(\mathrm{C})$.

To verify that $T$ satisfies condition (RCSC), consider the following cases.

Case-I: Let $x, y \in\left[0, \frac{4}{5}\right)$, then we have

$$
|T x-T y|=0 \leq \frac{1}{3}[|x-y|+|T x-y|+|x-T y|],
$$

$x, y \in\left[0, \frac{4}{5}\right)$.

Case-II: Let $x, y \in\left[\frac{4}{5}, 1\right]$, then

$$
|T x-T y|=\left|\frac{x}{2}-\frac{y}{2}\right|
$$

Since

$$
\begin{aligned}
& |x-y|>\left|\frac{x}{2}-\frac{y}{2}\right|=|T x-T y|, \\
& |T x-y|=\left|\frac{x}{2}-y\right|>\left|\frac{x}{2}-\frac{y}{2}\right|=|T x-T y|
\end{aligned}
$$

and

$$
|x-T y|=\left|x-\frac{y}{2}\right|>\left|\frac{x}{2}-\frac{y}{2}\right|=|T x-T y|,
$$

which implies that

$$
|T x-T y|<\frac{1}{3}[|x-y|+|T x-y|+|x-T y|]
$$

for all $x, y \in\left[\frac{4}{5}, 1\right]$.

Case-III: Let $x \in\left[0, \frac{4}{5}\right)$ and $y \in\left[\frac{4}{5}, 1\right]$ or $x \in\left[\frac{4}{5}, 1\right]$ and $y \in\left[0, \frac{4}{5}\right)$. Then

$$
|T x-T y|=\frac{y}{2} .
$$

Also,

$$
\frac{1}{3}[|x-y|+|T x-y|+|x-T y|]=\frac{1}{3}\left[y-x+y+\left|x-\frac{y}{2}\right|\right] .
$$


We now have two subcases as follows.

Case-III(A): $x \geq \frac{y}{2}$, then $\left|x-\frac{y}{2}\right|=x-\frac{y}{2}$, and by (3.5) we have

$$
\frac{1}{3}[|x-y|+|T x-y|+|x-T y|]=\frac{y}{2}=|T x-T y| .
$$

Case-III(B): $x<\frac{y}{2}$, then $\left|x-\frac{y}{2}\right|=\frac{y}{2}-x$, and by (3.5) we have

$$
\frac{1}{3}[|x-y|+|T x-y|+|x-T y|]=\frac{1}{3}\left[\frac{5 y}{2}-2 x\right]>\frac{1}{3}\left[\frac{5 y}{2}-y\right]=\frac{y}{2}=|T x-T y| .
$$

Hence $|T x-T y| \leq \frac{1}{3}[|x-y|+|T x-y|+|x-T y|]$ for all $x \in\left[0, \frac{4}{5}\right)$ and $y \in\left[\frac{4}{5}, 1\right]$.

Case-IV: Let $x \in\left[\frac{4}{5}, 1\right]$ and $y \in\left[0, \frac{4}{5}\right)$. By interchanging the role of $x$ and $y$ in Case-III, we can see that

$$
|T x-T y| \leq \frac{1}{3}[|x-y|+|T x-y|+|x-T y|]
$$

for all $x \in\left[\frac{4}{5}, 1\right]$ and $y \in\left[0, \frac{4}{5}\right)$.

In view of Case-I to Case-IV, we can say that $T$ satisfies condition (RCSC) for all $x, y \in C$.

\section{Competing interests}

The authors declare that they have no competing interests.

\section{Authors' contributions}

All authors contributed equally to the writing of this paper. All authors read and approved the final manuscript.

\section{Author details}

'School of Studies in Mathematics, Pt. Ravishankar Shukla University, Raipur, 492010 (C.G.), India. ${ }^{2}$ Department of Mathematics \& Informatics, University Politehnica of Bucharest, Bucharest, 060042, Romania.

\section{Acknowledgements}

The first author would like to thank the Rajiv Gandhi National Fellowship, University Grants Commission, Government of India under the grant (F1-17.1/2011-12/RGNF-ST-CHH-6632). The second author is supported by the Chhattisgarh Council of Science and Technology, India (MRP-2015).

Received: 27 May 2015 Accepted: 4 August 2015 Published online: 19 August 2015

\section{References}

1. Diaz, JB, Metcalf, FT: On the structure of the set of subsequential limit points of successive approximations. Bull. Am. Math. Soc. 73, 516-519 (1967)

2. Suzuki, T: Fixed point theorems and convergence theorems for some generalized nonexpansive mappings. J. Math. Anal. Appl. 340(2), 1088-1095 (2008)

3. Dhompongsa, S, Inthakon, W, Kaewkhao, A: Edelstein's method and fixed point theorems for some generalized nonexpansive mappings. J. Math. Anal. Appl. 350(1), 12-17 (2009)

4. Phuengrattana, W: Approximating fixed points of Suzuki-generalized nonexpansive mappings. Nonlinear Anal. Hybrid Syst. 5(3), 583-590 (2011)

5. Khan, SH, Suzuki, T: A Reich-type convergence theorem for generalized nonexpansive mappings in uniformly convex Banach spaces. Nonlinear Anal. 80, 211-215 (2013)

6. Karapınar, E: Remarks on Suzuki (C)-condition. In: Dynamical Systems and Methods. Springer, New York (2012)

7. Reich, S: Weak convergence theorems for nonexpansive mappings in Banach spaces. J. Math. Anal. Appl. 67, 274-276 (1979)

8. Mogbademu, AA: Convergence theorem of modified Noor iteration for nonlinear maps in Banach spaces. J. Adv. Math. Stud. 7(1), 56-64 (2014)

9. Saluja, GS: Weak convergence theorems for two asymptotically quasi-nonexpansive non-self mappings in uniformly convex Banach spaces. J. Nonlinear Sci. Appl. 7(2), 138-149 (2014)

10. Thakur, BS: Iterative approximation for common solution of a finite family of $m$-accretive operators. J. Adv. Math. Stud. 6(1), 34-42 (2013)

11. Zheng, Y: Attractive points and convergence theorems of generalized hybrid mapping. J. Nonlinear Sci. Appl. 8(4), 354-362 (2015)

12. Goebel, K, Kirk, WA: Topics in Metric Fixed Point Theory. Cambridge Studies in Advanced Mathematics, vol. 28. Cambridge University Press, Cambridge (1990) 
13. Agarwal, RP, O'Regan, D, Sahu, DR: Fixed Point Theory for Lipschitzian Type Mappings with Applications. Topological Fixed Point Theory and Its Applications, p. x+368. Springer, New York (2009)

14. Falset, JG, Kaczor, W, Kuczumow, T, Reich, S: Weak convergence theorems for asymptotically nonexpansive mappings and semigroups. Nonlinear Anal. 43, 377-401 (2001)

15. Kaczor, W: Weak convergence of almost orbits of asymptotically nonexpansive commutative semigroups. J. Math. Anal. Appl. 272, 565-574 (2002)

16. Diestel, J: Geometry of Banach Spaces, Selected Topics. Lecture Notes in Mathematics, vol. 285. Springer, New York (1975)

17. Senter, HF, Dotson, WG: Approximating fixed points of nonexpansive mappings. Proc. Am. Math. Soc. 44(2), 375-380 (1974)

Submit your manuscript to a SpringerOpen ${ }^{\odot}$ journal and benefit from:

- Convenient online submission

Rigorous peer review

- Immediate publication on acceptance

- Open access: articles freely available online

- High visibility within the field

- Retaining the copyright to your article 